\title{
Mapping of Winter Crops and Second-Crop Corn in the Paraná State-Brazil, Using Multitemporal Images From MODIS Sensor
}

\author{
R. N. Santos ${ }^{1}$, Erivelto Mercante ${ }^{1}$, Jerry Adriani Johann ${ }^{1}$, Carlos Henrique Wachholz de Souza ${ }^{2}$, \\ Carlos Eduardo Vizzotto Cattani ${ }^{1} \&$ Alex Paludo ${ }^{1}$ \\ ${ }^{1}$ Western Paraná State University, Cascavel, PR, Brazil \\ ${ }^{2}$ Federal University of Parana, Cascavel, PR, Brazil \\ Correspondence: Carlos Eduardo Vizzotto Cattani, Western Paraná State University (UNIOESTE), Cascavel, PR, \\ Brazil. Tel: 55-453-220-7366. E-mail: carloscattani@outlook.com.br
}

Received: September 5, 2018

Accepted: November 6, 2018

Online Published: January 15, 2019

doi:10.5539/jas.v11n2p477

URL: https://doi.org/10.5539/jas.v11n2p477

The research is financed by CAPES, CNPq, Araucaria foundation.

\begin{abstract}
The use of effective technologies for the monitoring of agricultural crops should seek methodologies that provide information regarding crop development, preferably before harvesting. The study of the monitoring and/or estimation of areas using vegetation indices derived from multitemporal data from MODIS sensors is being studied in the search for greater objectivity of the generated values. In this context, the objective of this study was to map areas with winter and second-crop corn using EVI/MODIS time series from the Terra and Aqua satellites, for the seasons from 2012 to 2014 in the Paraná state of Brazil. Accuracy analysis of the mappings was performed in spatial resolution images of $30 \mathrm{~m}$ (LISS-III and Landsat-8), to identify and validate the masks the crops of interest. The accuracy of the mapping obtained values of global precision $87.5 \%, 79.5 \%$, and $82.0 \%$, with Kappa index of 0.81, 0.69, and 0.73, in the 2012, 2013, and 2014 harvests, respectively. Comparing with data from the Brazilian Institute of Geography and Statistics (IBGE), the areas obtained by the mappings were underestimated for the second-crop corn in the 2012 and 2013 seasons and overestimated in 2014. The winter crops were overestimated for the three seasons investigated. The use of remote sensing data and techniques can contribute to a quick estimation of crop area information, and can assist in the surveys conducted by official institutions.
\end{abstract}

Keywords: EVI, Earth \& Aqua, vegetation index

\section{Introduction}

Brazil is globally recognized for its food production. This is mainly attributed to the availability of large agricultural areas, as well as technological advances in agriculture. The production of winter crops and second-crop corn is strong in the southern region of Brazil, where the climate favors their cultivation. Paraná State produced nearly $20 \%$ of second-crop corn and $59 \%$ of the total production of Brazilian winter crops in 2015 (IBGE, 2016). The notorious importance of the production of the 2 nd harvest corn and of the winter crops, led to the realization of studies that enable the estimation and monitoring of these crops using remote sensing as a tool to expedite the collection of such information.

Currently, the monitoring of agricultural production in Brazil is still largely performed by questioning farmers and/or cooperatives, known as sampling, carried out by the Brazilian official bodies. This technique requires a long period of time becoming costly (Pino, 2001; Mercante, 2007; Silva Junior et al., 2014). Prior knowledge of agricultural production is important for national economic control and for supplying the internal market. As such, it is vital to obtain effective technologies that quantify the forecast of agricultural crops and the information from cultivated areas.

In this regard, remote sensing techniques have been used in agricultural monitoring given that they allow for supervision of crop production dynamics. These dynamics follow seasonal patterns related to the biological plant life cycle, soil type, climatic variations, and agricultural practices (Atzberger, 2013). The use of satellite images with moderate spatial resolution and high temporal resolution, such as those from the Moderate Resolution 
Imaging Spectroradiometer (MODIS) sensor, allow for the analysis of spectral-temporal patterns of vegetation indices. In addition, MODIS has helped with the mapping and monitoring of agricultural activities in large areas (Mengue \& Fontana, 2015; Souza et al., 2015; Grzegozewski et al., 2016).

In this context, authors including Pan et al. (2012), Casady, Van Leeuwen, and Reed (2013), Potgieter, Lawson, and Huete (2013), Lobell, Ortiz-Monasterio, Sibley, and Sohu (2013), among others, have studied the agricultural monitoring and/or harvest estimation of winter crops using vegetation indices extracted from multitemporal images of the MODIS sensor. Despite obtaining satisfactory results, both the agro-climatic variables and the variety specificities are challenges in the development of more precise models to achieve these objectives.

Eberhardt et al. (2015) developed a method to identify and monitor agricultural areas cultivated with temporary summer crops using MODIS images in the state of Rio Grande do Sul. The conclusion was that the method made it possible to generate location maps of areas with soybean + corn (summer harvest), enabling agricultural monitoring. Fernandes et al. (2011) monitored altered areas in a rural property located in the state of Mato Grosso using multisensor data over six years for temporal analysis. Adami (2010) estimated the date of planting, date of change from the flowering phase to pod formation, and date of maturation of the soybean crop in the state of Paraná. This was completed through time series analysis of MODIS data and it was concluded that it is possible to estimate such variables using the MODIS sensor.

The objective of our study was to map the areas with winter crops (oats, rye, barley, wheat, and triticale) and second-crop corn in the state of Paraná, Brazil, using time series from MODIS sensor images, aboard the Terra and Aqua satellites, throughout the development cycle for the harvests from 2012 to 2014.

\section{Material and Methods}

The activities were completed at the Topography and Geoprocessing Laboratory (GeoLab) and Applied Statistics Laboratory (LEA) of the State University of Western Paraná (UNIOESTE), at the Cascavel campus. To complete the procedures, the following software was used: Environment for Visualizing Images (ENVI 5.0), developed by Exelis Visual Information Solutions (Boulder, Colorado, USA), and ArcGIS 10, developed by the Environmental Systems Research Institute (Redlands, California, USA). The Interactive Data Language (IDL 5.0) programming language was used in the development of automatic processing of MODIS images, as well as in data extraction from the spectral-temporal profiles of the Enhanced Vegetation Index (EVI) and in the generation of minimum and maximum EVI images (Esquerdo, 2007). The flowchart of activities completed in this research is displayed in Figure 1.

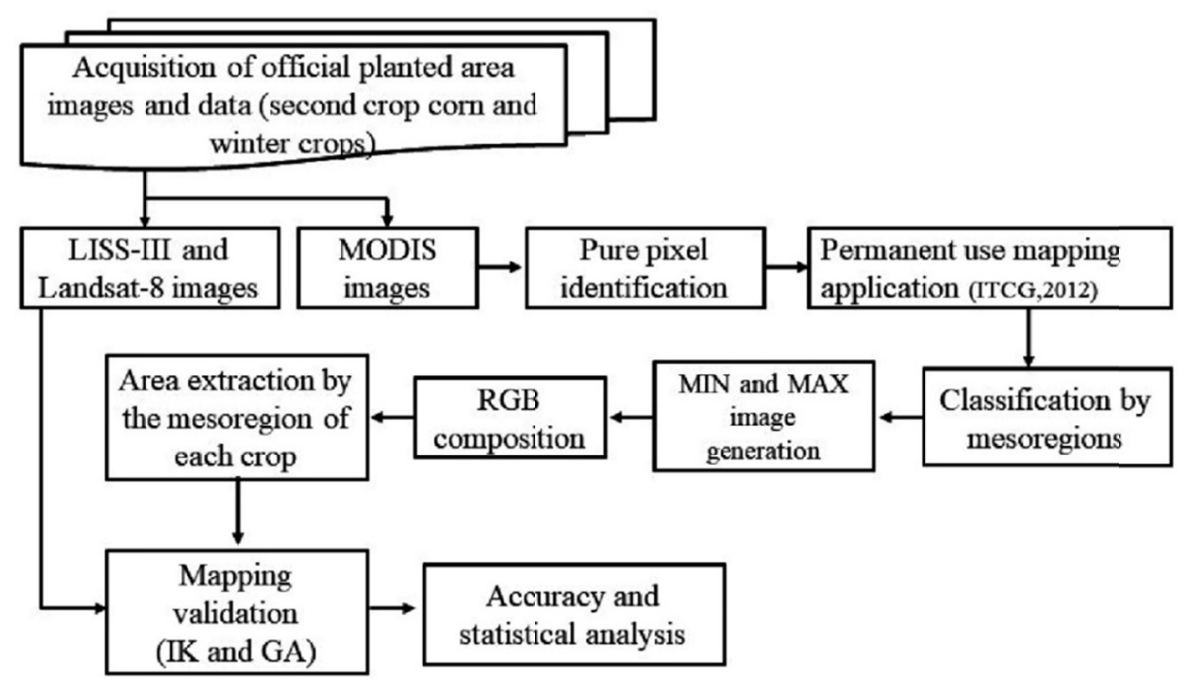

Figure 1. Activity flowchart for mapping winter crops and second-crop corn in Paraná State

\section{1 Area of Study and MODIS Images}

The study covered the 399 municipalities in Paraná State, in the southern region of Brazil. Given that seeding and harvesting dates are different depending on the region throughout the state, the ten mesoregions officially 
designated by the Brazilian Institute of Geography and Statistics (IBGE) (2016) were used: North Pioneering, North Central, Northwest, Central South, Central East, Central West, Western, Southwest, Southeast, and Greater Curitiba (Figure 2) (Johann et al., 2016). These were used only to choose the date for the elaboration of the minimum and maximum EVI images.

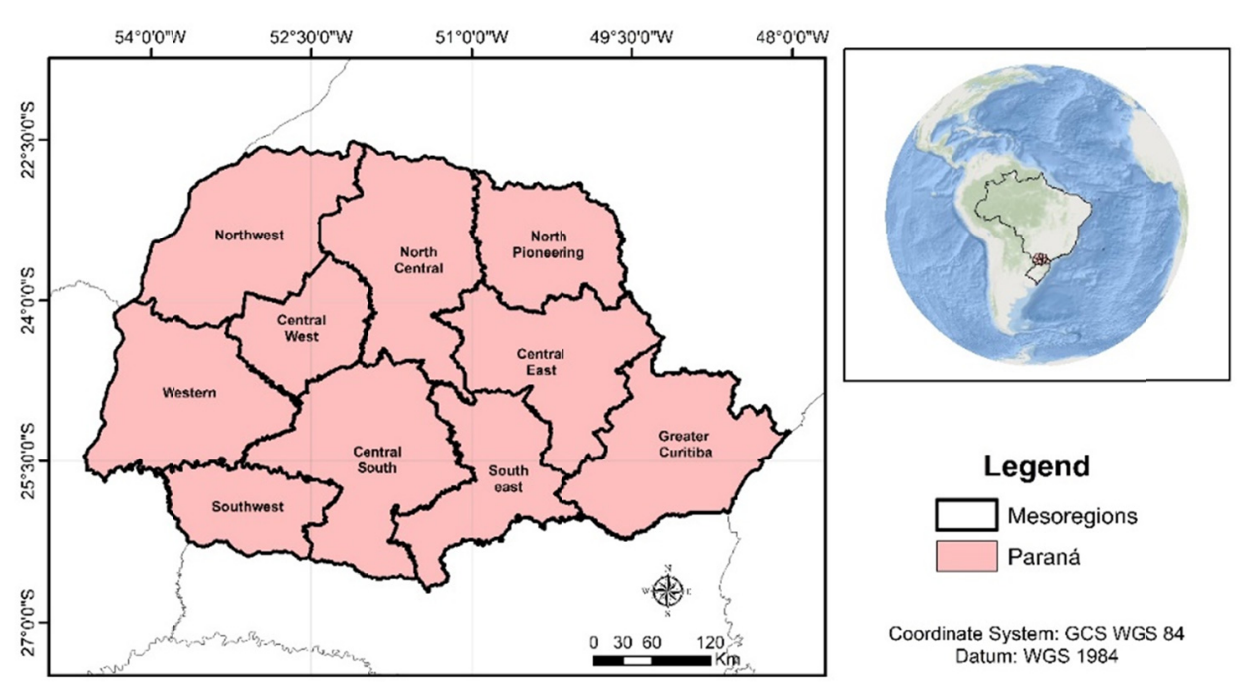

Figure 2. Location of the mesoregions in Paraná State

The satellite images for Paraná State were obtained from the Embrapa Informática database (EMBRAPA, 2015), and are part of the MOD13Q1 and MYD13Q1 products of the MODIS sensors aboard the Terra and Aqua satellites, respectively. These provide data, including vegetation indices with spatial resolution of $250 \mathrm{~m}$ and temporal resolution of 16 days. For this study, EVI images of tile h13v11 were used. These images display the entire growing distinct cycle of the winter crops and second-crop corn for the harvests of 2012, 2013, and 2014, and are presented in Table 1.

Table 1. Dates of the Terra and Aqua satellite images used for this study

\begin{tabular}{llllll}
\hline & \multicolumn{2}{c}{ Second crop corn } & & \multicolumn{2}{c}{ Winter crops } \\
\cline { 2 - 3 } \cline { 5 - 6 } \cline { 5 - 6 } & Terra Satellite & Aqua Satellite & & Terra Satellite & Aqua Satellite \\
\hline 2012 & January 01 to July 27 & January 09 to July 19 & & April 06 to October 31 & April 17 to November 08 \\
2013 & January 01 to July 12 & January 09 to July 04 & & April 07 to November 17 & April 15 to November 09 \\
2014 & January 01 to June 26 & January 09 to June 18 & & April 07 to November 17 & April 15 to November 09 \\
\hline
\end{tabular}

\subsection{Pure Pixel Identification}

With the help of both medium spatial resolution images from the Linear Imaging Self-Scanner (LISS-III) sensor, abroad the ResourceSat-1 satellite, and the Operational Land Imager (OLI) sensor, abroad the Landsat- 8 satellite, obtained from the databases of the National Institute for Space Research (INPE) and the U.S. Geological Survey (USGS), respectively, it was possible to identify plots belonging to winter crops (oats, barley, rye, wheat, and triticale) and second-crop corn. This was achieved by checking pixel samples that express only the spectral pattern of each studied crop in the pixel dimensions of the MODIS images $(250 \times 250 \mathrm{~m})$.

The dates of the LISS-III sensor images used in the study comprised the period from 07/03/2013 (for maize 2nd harvest) and $05 / 28 / 2013$ (for winter crops). The dates of the OLI sensor images used in the study comprised the periods from $04 / 17 / 2013$ to $08 / 23 / 2013$ and $04 / 27 / 2014$ to $06 / 30 / 2014$ (for maize 2 nd harvest) and $07 / 27 / 2013$ a 23/08/2013 and 05/18/2014 to 08/08/2014 (for the winter crops). The colored compositions used for the LISS-III sensor images were RGB-453 and for the OLI sensor it was RGB-564.

To complete this process, visual image interpretation techniques were utilized according to Mercante, Lima, Justina, Uribe-Opazo, and Lamparelli (2012) along with an evaluation of the EVI MODIS spectral-temporal 
profile. While the MODIS images from the year of study were compiled in a single file and ordered by date (Figures 3 and 4aa), the OLI and/or LISS-III image was opened on the date corresponding to the period for the studied culture (Figures 3 and 4b). With help from the "Spectral Profile" tool included in ENVI 5.0, pure pixels were evaluated by checking seeding and harvesting dates through the spectral-temporal profile (Figures 3 and $4 c)$.

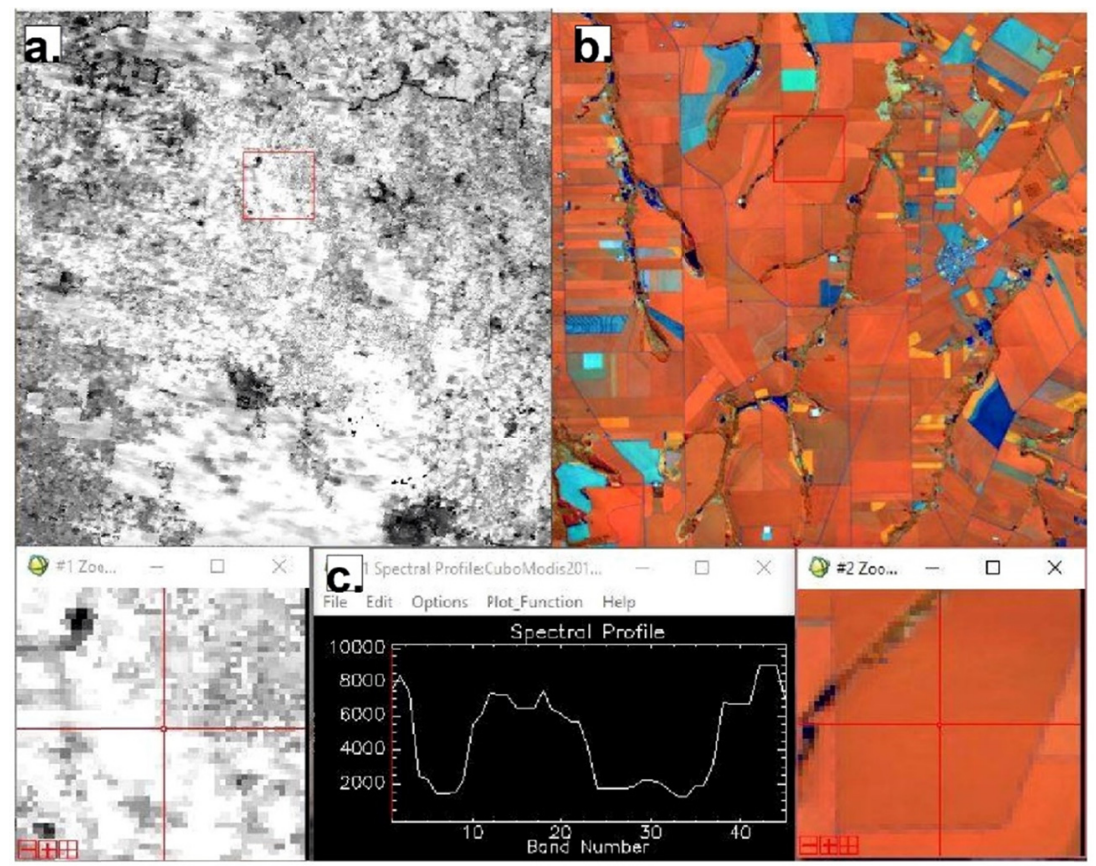

Figure 3. Identification of the second crop corn in EVI MODIS (a) and OLI images (b), as well as in the spectral-temporal profile (c)

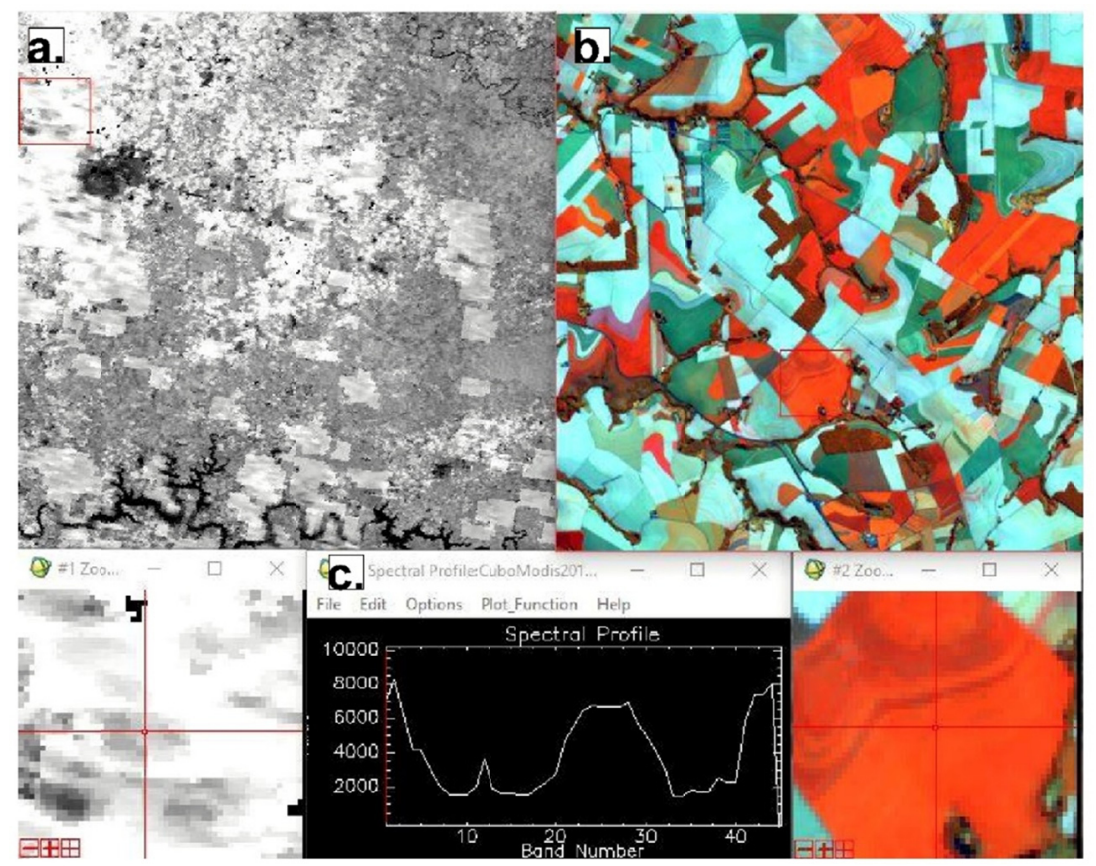

Figure 4. Identification of the winter crops in EVI MODIS (a) and OLI images (b), as well as in the spectral-temporal profile (c) 


\subsection{Generation of Maximum and Minimum EVI Images}

The methodology proposed by Johann et al. (2012), which consists of using multiple MODIS images to generate the EVI "minimum and maximum images", was used to map the winter crops and the second-crop corn. An interactive data language (IDL) system, developed by Esquerdo (2007), was employed to extract image data.

The "minimum EVI image" represents the pre-planting phase until the initial crop development and "maximum EVI image" represents the full development or growth peak of the crops. In the process of defining the dates, the EVI spectral-temporal profiles were analyzed for each crop separately. Seeding periods and full crop development were checked and the fact that growing seasons are different was considered (Adami, 2010; Johann et al., 2012; Souza et al., 2015) (Figure 5).
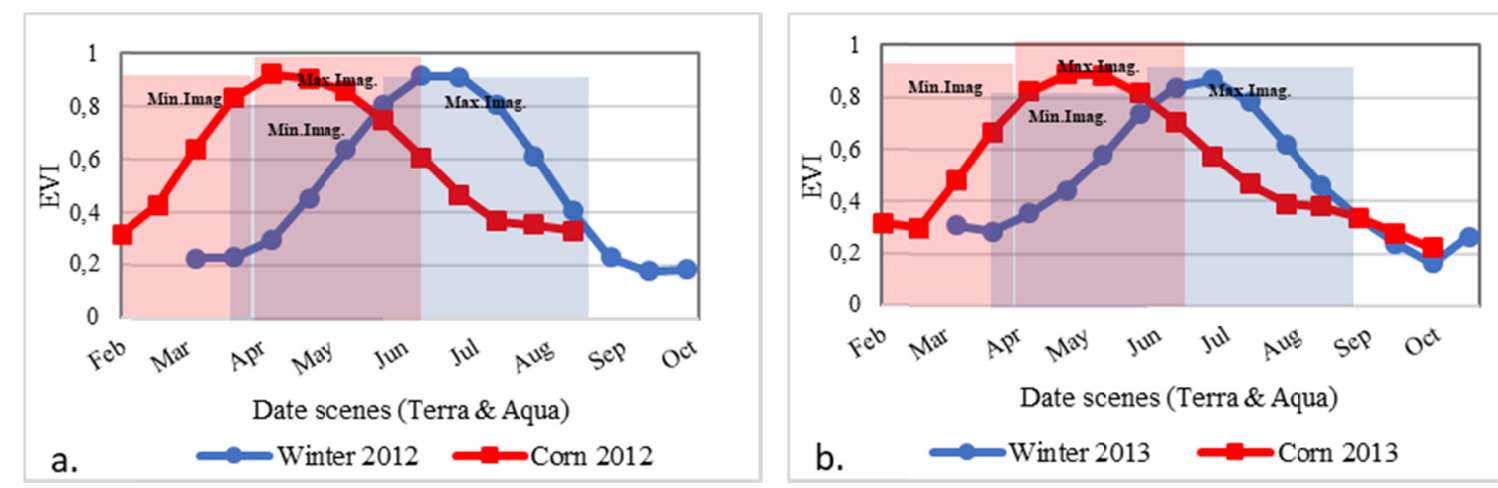

b.

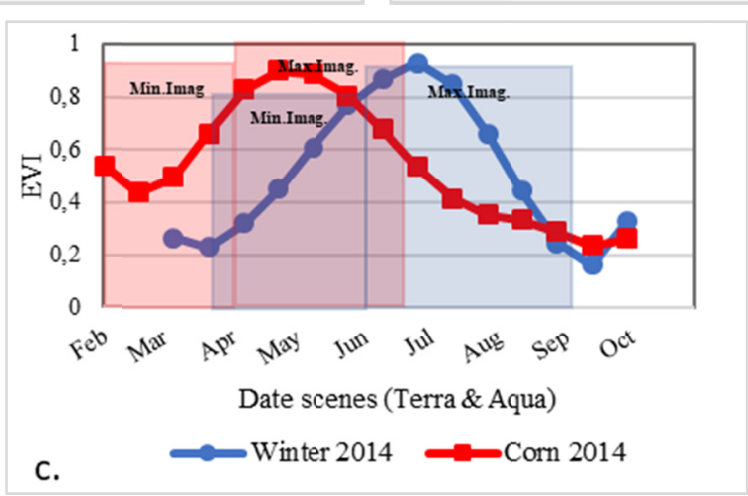

Figure 5. Temporal profile of the winter crops and second-crop corn: a. 2012; b. 2013; c. 2014

\subsection{Color Composition and RGB Extraction}

The RGB color composition was performed using the ENVI 5.0 software. The winter crops and second-crop corn were worked on separately. As such, the maximum EVI image was placed on the R channel and the minimum EVI image was placed on the $\mathrm{G}$ and $\mathrm{B}$ channels. This resulted in a colored composition in which the red areas represent the studied cultures (Johann et al., 2012).

Subsequently, the original EVI values were transformed to gray levels (GL), with 8 bits (0-255), and RGB extraction was carried out. This is based on the extraction of areas of interest, using cut values in R and GB channels, yielding only the mapping of the culture of interest (Johann et al., 2012). This method separates the GL cut values for the $\mathrm{R}$ channel and for the $\mathrm{G}$ and $\mathrm{B}$ channels, set by the user during simulation.

For each test, the classified pixels were those with values greater than the cut set for the $\mathrm{R}$ channel and less than the cut set for the $\mathrm{G}$ and $\mathrm{B}$ channels, resulting in the winter crops and second-crop corn. The ideal cut value was defined by superimposing masks on the medium spatial resolution images. It was then confirmed that the pixels coincided with the areas cultivated with the studied crops.

The mapping of maize 2 nd harvest and the winter washes were performed independently, it was performed between the masks to be evaluated as overlapping localized areas, that is, if we forgot areas common to the crops studied. During the pure pixel verification, areas cultivated with second-crop corn and later with a winter crop were observed, especially during the 2014 harvest. This justifies the crop overlap observed in the figure 5- C. 
The overlapping areas were located in the spatial mean resolution images to identify which crop was actually being grown in that specific area for a correct classification later.

\subsection{Accuracy Analysis}

The methodology adopted to perform the mapping accuracy evaluation using an error matrix is called panel sampling (Foody, 2002).

We used 400 randomly distributed sampling points on the mapping of each crop, with $50 \%$ being selected from the target of interest (winter crop or second-crop corn) and 50\% from outside the mapping. The point evaluation, completed to determine which class they belong to, was performed by visual inspe ction using satellite images from LISS-III and OLI. The overlapping areas were correctly classified according to the crop identification in the medium spatial resolution images. Global accuracy (GA), Kappa index (KI), and inclusion and omission errors were calculated using the error matrix.

\subsection{Area Comparison Analysis}

The area data obtained by mapping the 2012, 2013, and 2014 harvests were compared with official harvested area data, made available by the IBGE (2016), using Spearman's rank correlation coefficient (rs). The statistical indicators used were the Mean Error (ME) (Equation 1) and the Willmott refined agreement index (dr) (Equation 2). The latter determines method accuracy and indicates the degree of deviation from the values estimated by the mapping and those reported by official bodies. This index varies from -1 to 1 , with values that are positive and close to 1 , indicating a better agreement.

$$
\begin{aligned}
\mathrm{ME} & =\frac{1}{\mathrm{n}} \times \sum_{\mathrm{i}=1}^{\mathrm{n}}(\mathrm{O}-\mathrm{E}) \\
\mathrm{dr} & =1-\frac{\sum_{\mathrm{i}=1}^{\mathrm{n}}|\mathrm{E}-\mathrm{O}|}{2 \sum_{\mathrm{i}=1}^{\mathrm{n}}(|\mathrm{O}-\overline{\mathrm{O}}|)}
\end{aligned}
$$

Where, n: number of municipalities; O: official crop area; E: crop area obtained from mapping; $\bar{O}$ : official mean crop area.

\section{Results and Discussion}

The second-crop corn and winter crops were mapped separately. Individual minimum and maximum EVI images, in which the areas in red represent the cultures of interest, were then created for each culture and crop (Figure 6a, $6 \mathrm{~b}, 6 \mathrm{c}, 6 \mathrm{~g}, 6 \mathrm{~h}$, and 6i). While mapping the winter crops and second-crop corn, results for the former were obtained when the GL cut values were defined at R165 and GB130 for the 2012 harvest and R135 and GB130 for the 2013 and 2014 harvests. As for the second crop corn, results were obtained when 140 was defined as the cut value for the R channel and 130 for the $\mathrm{G}$ and $\mathrm{B}$ channels, for all three harvests. Upon observing the culture spatial distribution shown in Figure 6, note that the western region is the largest producer of second-crop corn in the state and that the south central, central western, and central north regions stand out for their winter crops.
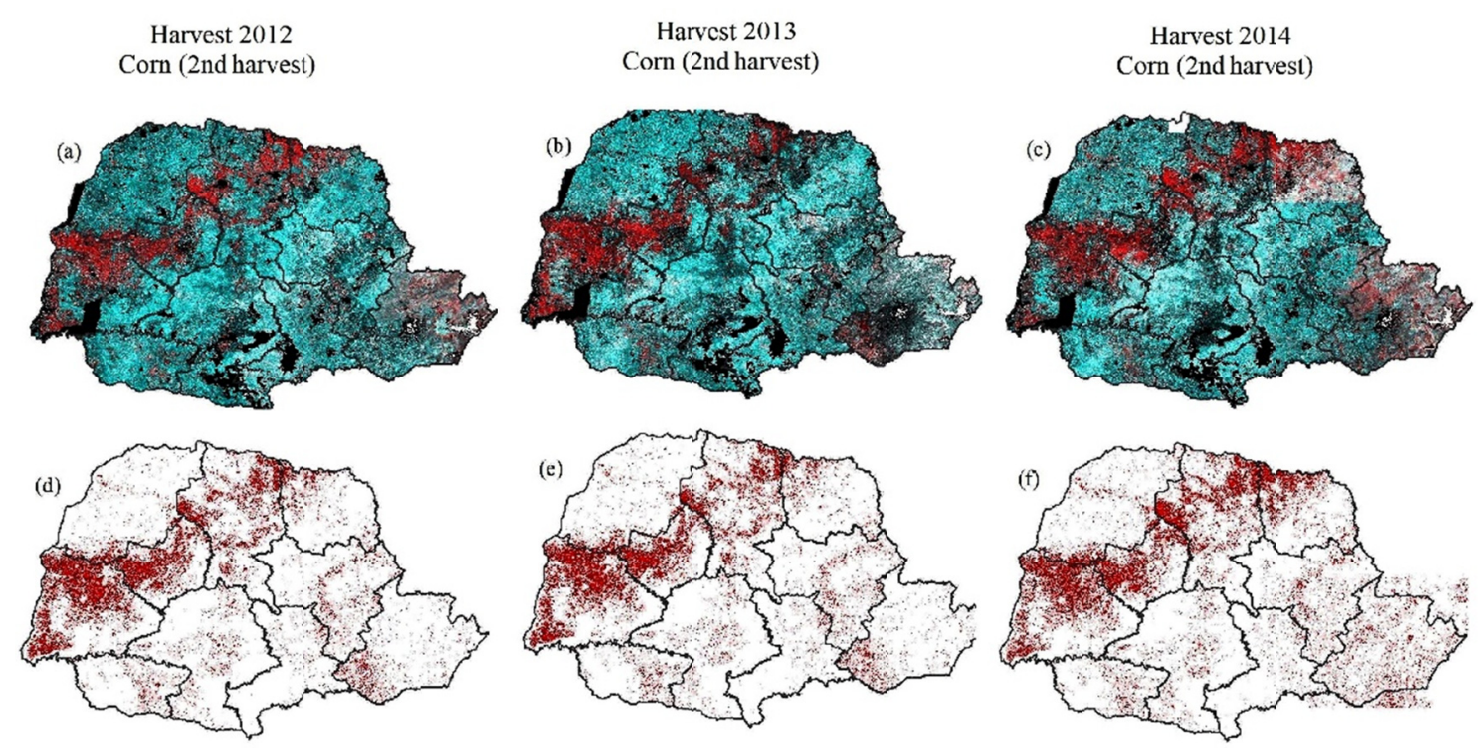

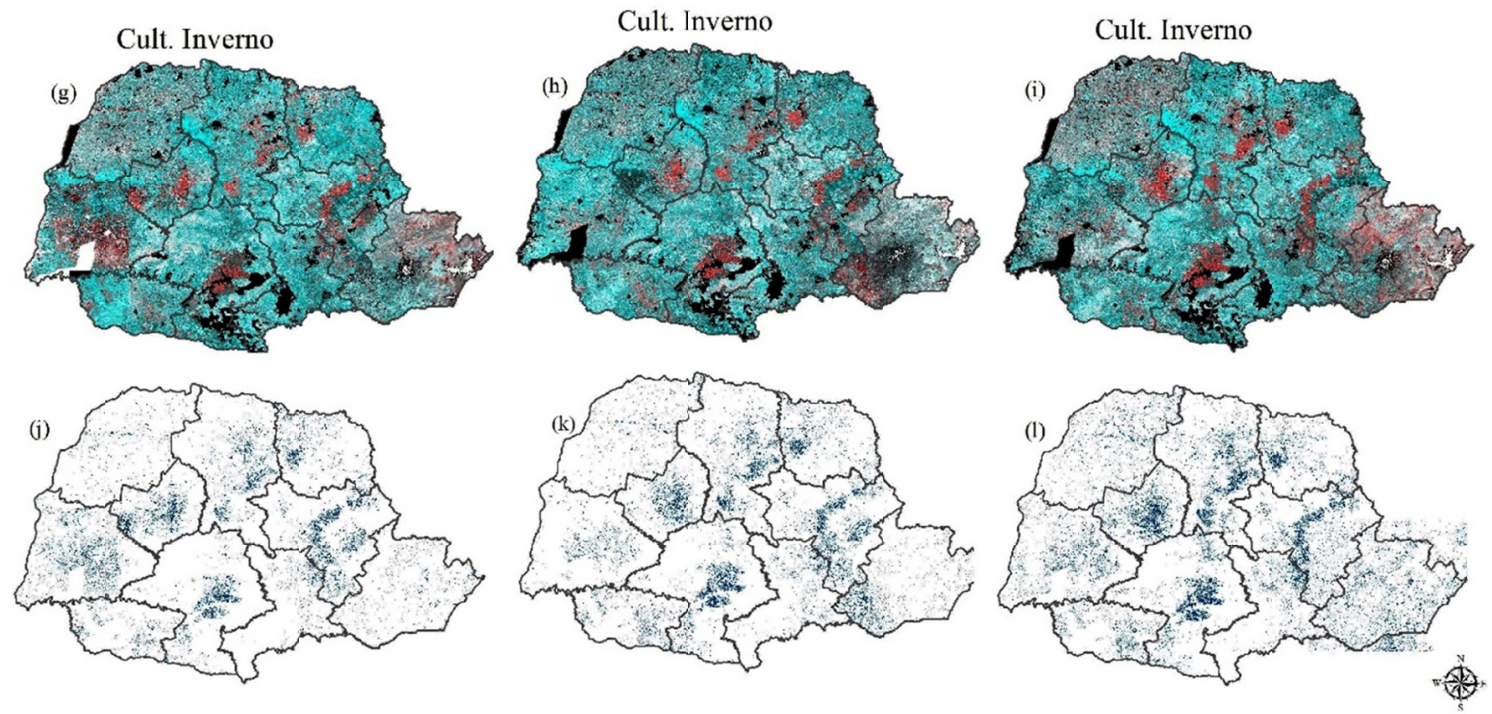

Figure 6. Spatial distribution of second-crop corn 2012 (a, d), 2013 (b, e), and 2014 (c, f) and winter crops for the $2012(\mathrm{~g}, \mathrm{j}), 2013$ (h, k), and 2014 (i, l) harvests in Paraná State

\subsection{Mapping Accuracy Analysis}

Analyzing the results of accuracy for the mappings, it was verified GA for the 2012 harvest was $87.5 \%$, reaching the minimum accepted value of $85.0 \%$ according to Foody (2002). However, the obtained values for the 2013 and 2014 harvests were $79.5 \%$ and $82.0 \%$. The KI was classified as excellent for the 2012 harvest and as very good for the 2013 and 2014 harvests, according to the classification described by Landis and Koch (1977).

The accuracy results found by Potgieter, Lawson, and Huete (2013), when mapping the winter crop types in Queensland (Australia) using EVI MODIS images, were a KI higher than 0.86 and a GA of $96.0 \%$. While mapping cropping systems in China using EVI MODIS images, Li, Friedl, Xin, Gray, Pan, and Frolking (2014) observed a GA of $91.0 \%$. Souza, Mercante, Johann, Lamparelli, and Uribe-Opazo (2015), mapped summer crops in Paraná using EVI MODIS and obtained GA values of $83.3 \%$ and $80.0 \%$, and a KI of 0.74 and 0.69 in the 2010/11 and 2011/12 harvests, respectively.

Another way of assessing accuracy is by analyzing the IE and OE present in the classification (Congalton \& Green, 1999). It was observed that the mappings for the 2012, 2013, and 2014 harvest averaged an IE of 12.2\%, $20.1 \%$, and $17.3 \%$, respectively. This means that the method misclassified these sites as crop areas of interest, when they were in fact other targets. The OE was on average $12.5 \%, 20.5 \%$, and $18.0 \%$ for the 2012,2013 and 2014 harvests, respectively. This indicates the proportion of samples that were excluded from the class to which they belonged.

\subsection{Comparison of Mapped Areas With Official Data}

The comparison between the data of the area estimated by the mapping and the data reported by IBGE was performed for the three studied harvests and is shown in Table 2. For the second-crop corn, the areas obtained by the mapping were smaller than the official ones provided by the IBGE for the 2012 and 2013 harvests. The percentage difference varied from $1 \%$ to $6.14 \%$. For the 2014 harvest, the areas were overestimated by $22.40 \%$. Meanwhile, the winter crop areas were overestimated when compared to official data, with percentage differences of $0.28 \%, 2.53 \%$, and $1.67 \%$ for the 2012,2013 , and 2014 harvests, respectively. This could mean that the mask is misclassifying the pixels or that the mixed pixels are exercising some influence on classification accuracy, according to Zhong et al. (2014). During the harvests, the areas cultivated with second-crop corn decreased in size, while the winter crop areas increased. This indicates a potential replacement of second-crop corn by winter crops. 
Table 2. Differences between the performed mapping (second-crop corn and winter crops) and official area (IBGE) for Paraná State, Brazil

\begin{tabular}{lllll}
\hline Crops & Variables & 2012 & 2013 & 2014 \\
\hline \multirow{4}{*}{ Second crop corn } & IBGE area (ha) & $2,039,241$ & $2,150,710$ & $1,898,614$ \\
& Mapped area (ha) & $2,018,850$ & $2,018,675$ & $2,323,837$ \\
& Difference (Mapping-IBGE) & $-20,391$ & $-132,035$ & 425,223 \\
& Difference (\%) & $-1.00 \%$ & $-6.14 \%$ & $22.40 \%$ \\
\multirow{2}{*}{ Winter } & IBGE area (ha) & 935,230 & $1,125,265$ & $1,510,138$ \\
& Mapped area (ha) & 937,825 & $1,153,752$ & $1,535,301$ \\
& Difference (Mapping-IBGE) & 2,595 & 28,487 & 25,163 \\
& Difference (\%) & $0.28 \%$ & $2.53 \%$ & $1.67 \%$ \\
\hline
\end{tabular}

Note. Source: IBGE (2016).

Crusiol et al. (2016) mapped agricultural areas of the municipality of Londrina, Paraná, Brazil, for five summer harvests. When comparing the results obtained with official IBGE data, an overestimation of $31.93 \%$ and $44.72 \%$ in relation to official data in the $1998 / 1999$ and 2000/2001 harvests, respectively, was observed. This was in addition to an underestimation of $3.96 \%$ to $14.80 \%$ in the $2001 / 2002,2006 / 2007$, and $2008 / 2009$ harvests.

Based on EVI/MODIS spectral-temporal behavior, Mengue and Fontana (2015) mapped summer crops in the state of Rio Grande do Sul, Brazil. When comparing the results obtained with the official IBGE data, an underestimation of $11.13 \%$ for soybean and an overestimation of $16.72 \%$ for irrigated rice were noted.

Figure 7 displays the statistical indices $\mathrm{ME}$ and $\mathrm{dr}$, and the rs value, with the second-crop corn yielding better results when compared to the winter crops. By analyzing the ME, it was confirmed that the area obtained by the mapping was underestimated on average by 7,621.26 ha for the 2012 and 2013 harvests and overestimated by 42,522.34 ha in 2014 for the second-crop corn. Meanwhile, the method overestimated by an average of 1,874.85 ha in the harvest of winter crops for all three years. When evaluating rs for the second-crop corn, there was a variation from 0.72 to 0.75 . This indicates a strong correlation between the official data and the estimated data. On the other hand, rs varied from 0.40 to 0.60 for winter crops, indicating a moderate correlation between the official data and the data obtained by mapping to Andriotti (2009). The dr determines the accuracy of the method with positive values and close to 1 indicating better agreement, so the mapping for the 2 nd crop corn presented $\mathrm{dr}$ of 0.84 on average and for the winter crops dr of 0.56 on average. 

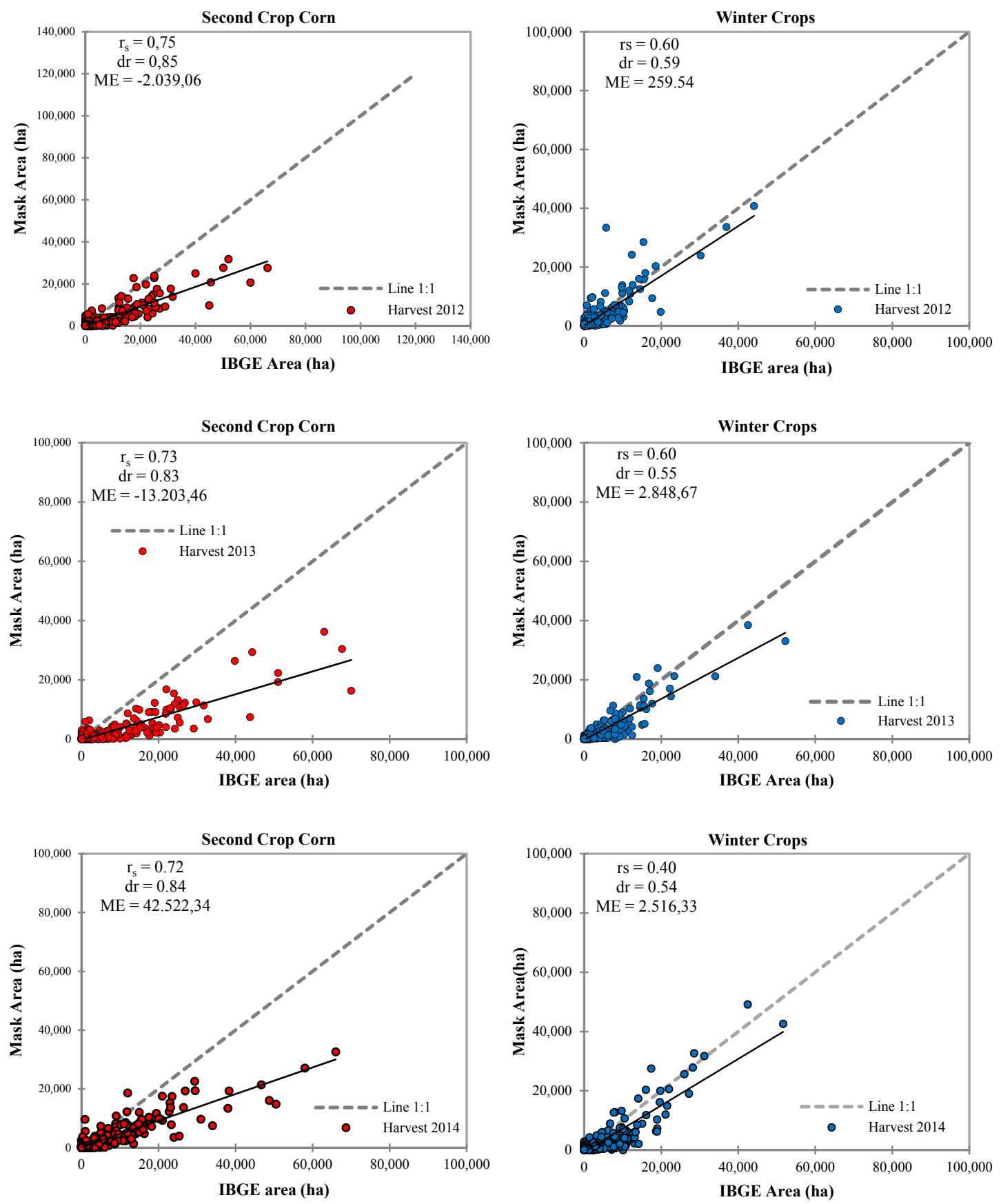

Figure 7. Relationship between data on official area (ha) and data obtained by the mappings (ha) of corn Second-crop corn (in red) and winter crops (in blue) for Paraná State-Brazil

Note. ME: Mean error; dr: Willmott refined agreement index; rs: Spearman's rank correlation coefficient.

MODIS sensor data, as well as its products, have been employed by different authors using different methodologies. Kogan et al. (2013) evaluated the use of MODIS sensor data to predict winter wheat productivity in Ukraine. They used a regression model based on NDVI temporal data, meteorological data, and biophysical models. Their results verified that the NDVI model and biophysical model were overestimated between $32 \%$ and $21 \%$ (for the months of April and May, respectively) in 2010 and underestimated between $21 \%$ and $14 \%$ (for the months of April and May, respectively) in 2011, in relation to official statistics. Li et al. (2014) proposed an algorithm for agricultural mapping using a MODIS sensor EVI time series. This resulted in field estimates that are consistent with the official data and in an accuracy assessment indicating $91 \%$ accuracy for the agricultural 
areas.

Based on mapping results, this study confirmed that the estimated values (mapping) differed between $-6.14 \%$ and $22.40 \%$, when compared to the official data. However, the official statistics are based on research obtained from farmers and cooperatives and agricultural finance data. These values are usually generalized, resulting in relative and imprecise data (Pino, 2001; Antunes et al., 2012; Johann et al., 2012). Antunes, Mercante, Esquerdo, Lamparelli, and Rocha (2012) verified that estimates given by official bodies such as SEAB/DERAL are obtained subjectively using planting intention surveys performed by sampling. According to Pino (2001), the IBGE uses subjective municipal information based on opinions of technical and economic agents. This does not allow for an accurate quantitative analysis of the errors involved and is susceptible to manipulation.

When evaluating the mapping accuracy in relation to the reference (using medium spatial resolution images - LISS-III and OLI), according to Foody (2002), the accepted minimum value indicating the success of the classification was standardized at $85 \%$, and Landis and Koch (1977) state that the KI closer to 1 indicates better quality in the classification. Therefore the results for GA and the KI were satisfactory. A factor that influences mapping is the size of the agricultural areas, which are often small, confusing the mapping and increasing the probability of pixels mixing. Souza, Mercante, Johann, Lamparelli and Uribe-Opazo (2015) mapped soybean and corn crops and concluded that soybean cultivation was better mapped compared to corn. This is probably owing to the large areas planted with soybean in the state, which makes mapping using the MODIS sensor easier. Corn cultivation is usually completed in smaller and more dispersed areas, increasing the probability of mixed pixels.

Zhong, Hu, Yu, Gong, and Biging (2014), mapped soybean and corn in the state of Paraná and confirmed that the mixed pixel effect represents a relevant influence on classification accuracy, and that this effect depends on several pixel mixing patterns between the regions of the state. As such, in highly cultivated regions, many mixed pixels are influenced by crops and can be classified as agricultural areas. This results in overestimation of cultivated areas. On the other hand, in regions with no and/or very small cultivated areas, mixed pixels can be dominated by non-agricultural areas, resulting in an underestimation of cultivated areas (Li et al., 2014). Another possibility could be the spatial resolution of the MODIS sensor $(250 \mathrm{~m})$, given that in small agricultural areas (below the spatial resolution of the sensor), the effects of spatial heterogeneity have been noted (Li et al., 2014).

The use of MODIS favors the mapping of agricultural areas based on temporal resolution. Nonetheless, given the image spatial resolution, the difficulty in mapping small areas using this sensor generates some errors in the final results. Further studies need to be carried out to minimize these obstacles in the use of the MODIS sensor.

\section{Conclusions}

The use of MODIS sensor multitemporal images along with the utilized classification method allow for the mapping of winter crops and second-crop corn. This enabled the identification, separation, and mapping of these crops for the state of Paraná, Brazil.

The errors in the comparison between the estimated values (mappings) and the observed ones (IBGE) were in line with those presented in the literature. Spatial accuracy between mapping and reference data was satisfactory, confirming the effectiveness of the applied methodology.

The use of remote sensing data and techniques can contribute to a quick estimation of crop area information and can assist with the surveys conducted by official institutions.

\section{References}

Adami, M. (2010). Estimativa da data de plantio da soja por meio de séries temporais de imagens MODIS (Doctoral dissertation, Instituto Nacional de Pesquisas Espaciais, Sensoriamento Remoto, São José dos Campos, Brazil).

Andriotti, J. L. S. (2009). Fundamentos de Estatística e Geoestatística. Editora Unisinos: São Leopoldo, Brazil.

Antunes J. F. G., Mercante, E., Esquerdo, J. C. D. M., Lamparelli, R. A. C., \& Rocha J. V. (2012). Estimativa de área de soja por classificação de imagens normalizada pela matriz de erros. Pesquisa Agropecuária Brasileira, 47(9), 1288-1294. https://doi.org/10.1590/S0100-204X2012000900014

Atzberger, C. (2013). Advances in Remote Sensing of Agriculture: Context Description, Existing Operational Monitoring Systems and Major Information Needs. Remote Sensing, 5, 949-981. https://doi.org/10.33 90/rs5020949 
Casady, G. M., Van Leeuwen, W. J. D., \& Reed, B. C. (2013). Estimating winter annual biomass in the Sonoran and Mojave Deserts with satellite and ground based observations. Remote Sensing, 5, 909-926. https://doi.org/10.3390/rs5020909

Congalton, R. G., \& Green, K. (1999). Assessing the accuracy of remotely sensed data: Principles and practices (2nd ed.). Boca Raton, FL: CRC Press.

Crusiol, L. G. T., Neto, O. C. P., Nanni, M. R., Gualberto, A. A. S, Furlanetto, R. H., \& Silva Junior, C. A. (2016). Mapeamento de áreas agrícolas na safra de verão a partir de imagens Landsat frente aos dados oficiais. RevistaAgro@mbiente On-line, 10(4),287-298. https://doi.org/10.18227/1982-8470ragro.v10i4.3098

Eberhardt, I. D. R., Luiz, A. J. B., Formaggio, A. R., \& Sanches, I. D. (2015). Detecção de áreas agrícolas em tempo quase real com imagens Modis. Pesquisa Agropecuária Brasileira, 50(7), 605-614. https://doi.org/ 10.1590/S0100-204X2015000700010

EMBRAPA (Embrapa Informática Agropecuária). (2015). Sistema de Análise Temporal da Vegetação (SATVeg). Retrived June 10, 2016, from https://www.satveg.cnptia.embrapa.br/satveg/login.html.

Esquerdo, J. C. D. M. (2007). Utilização de perfis multi-temporais do NDVI/AVHRR no acompanhamento da safra de soja no oeste do Paraná (Doctoral dissertation, Universidade Estadual de Campinas, Engenharia Agrícola, Campinas, Brasil).

Fernandes, R. R., Nunes, G. M., \& Drescher, R. (2011). Monitoramento de propriedades rurais através de dados multisensores em nível orbital. Ambiência, 7(1), 75-87. https://doi.org/10.5777/ambiencia.2011.01.06

Foody, G. M. (2002). Status of land cover classification accuracy assessment. Remote Sensing of Environment, 80(1), 185-201. https://doi.org/10.1016/S0034-4257(01)00295-4

Grzegozewski, D. M., Johann, J. A., Uribe-Opazo, M. A., Mercante, E., \& Coutinho, A. C. (2016). Mapping of the soya bean and corn crops in the State of Paraná using EVI imagens from the MODIS sensor. International Journal of Remote Sensing and Remote Sensing Letters, 37(6), 1257-1275. https://doi.org/ 10.1080/01431161.2016.1148285

IBGE (Instituto Brasileiro de Geografia e Estatística). (2016). Levantamento sistemático da produção agrícola. Retrived November 17, 2016, from http://www.sidra.ibge.gov.br

Johann, J. A., Rocha, J. V., Duft, D. G., \& Lamparelli, R. A. C. (2012). Estimativa de áreas com culturas de verão no Paraná, por meio de imagens multitemporais EVI/Modis. Pesquisa Agropecuária Brasileira, 47(9), 1295-1306. https://doi.org/10.1590/S0100-204X2012000900015

Johann, J. A., Becker, W. R., Uribe-Opazo, M. A., \& Mercante, E. (2016). Uso de imagens do sensor orbital Modis na estimação de datas do ciclo de desenvolvimento da cultura da soja para o estado do Paraná-Brasil. Engenharia Agrícola, 36(1), 126-142. https://doi.org/10.1590/1809-4430-Eng.Agric.v36n1p126-1 42/2016

Kogan, F., Kussul, N., Adamenko, T., Skakun, S., Kravchenko, O,. Kryvobok, O., ... Lavrenyuk, A. (2013). Winter wheat yield forecasting in Ukraine based on Earth observation, meteorological data and biophysical models. International Journal of Applied Earth Observation and Geoinformation, 23, 192-203. https://doi.org/10.1016/j.jag.2013.01.002

Landis, J. R., \& Koch, G. G. (1977). The measurement of observer agreement for categorical data. Biometrics, 33(1), 159-174. https://doi.org/10.2307/2529310

Li, L., Friedl, M. A., Xin, Q., Gray, J., Pan, Y., \& Frolking, S. (2014). Mapping crop cycles in China using MODIS-EVI time series. Remote Sensing, 6, 2473-2493. https://doi.org/10.3390/rs6032473

Lobell, D. B., Ortiz-Monasterio, J. I., Sibley, A. M., \& Sohu, V. S. (2013). Satellite detection of earlier wheat sowing in India and implications for yield trends. Agricultural Systems, 115, 137-143. https://doi.org/ 10.1016/j.agsy.2012.09.003

Mengue, V. P., \& Fontana, D. C. (2015). Assessment of spectral-temporal dynamics for mapping the main summer crops in the Rio Grande do Sul State. Bragantia, 74(3), 331-340. https://doi.org/10.1590/16784499.0452

Mercante, E. (2007). Dinâmica espectral da cultura da soja ao longo do ciclo vegetativo e sua relação com a produtividade na região do oeste do Paraná (Doctoral dissertation, Universidade Estadual de Campinas, Engenharia Agrícola.Campinas, Brazil).

Mercante, E., Lima, L. E P., Justina, D. D. D., Uribe-Opazo, M. A., \& Lamparelli, R. A. C. (2012). Detection of 
soybean planted areas through orbital images based on culture spectral dynamics. Revista Engenharia Agricola, 32(5), 920-931. https://doi.org/10.1590/S0100-69162012000500011

Mkhabela, M. S., Bullock, P., Raj, S., Wang, S., \& Yang, Y. (2011). Crop yield forecasting on the Canadian Prairies using MODIS NDVI data. Agricultural and Forest Meteorology, 151, 385-393. https://doi.org/ 10.1016/j.agrformet.2010.11.012

Pan, Y., Li, L., Zhang, J., Liang, S., Zhu, X., \& Sulla-Menashe, D. (2012). Winter wheat area estimation from MODIS-EVI time series data using the Crop Proportion Phenology Index. Remote Sensing of Environment, 119, 232-242. https://doi.org/10.1016/j.rse.2011.10.011

Pino, F. A. (2001). Estimação subjetiva de safras agrícolas. Informações Econômicas, 31(6), 55-58.

Potgieter, A. B., Lawson, K., \& Huete, A. R. (2013). Determining crop acreage estimates for specific winter crops using shape attributes from sequential MODIS imagery. International Journal of Applied Earth Observation and Geoinformation, 23, 254-263. https://doi.org/10.1016/j.jag.2012.09.009

Silva Junior, C. A., Frank, T., \& Rodrigues, T. C. S. (2014). Discriminação de áreas de soja por meio de imagens EVI/MODIS e análise baseada em geo-objeto. Revista Brasileira de Engenharia Agrícola e Ambiental, 18(1), 44-53. https://doi.org/10.1590/S1415-43662014000100007

Souza, C. H. W., Mercante, E., Johann, J. A., Lamparelli, R. A. C, \& Uribe-Opazo, M. A. (2015). Mapping and discrimination of soya bean and corn crops using spectro-temporal profiles of vegetation indices. International Journal of Remote Sensing, 36(7), 1809-1824. https://doi.org/10.1080/01431161.2015.102 6956

Zhong, L., Hu, L., Yu, L., Gong, P., \& Biging, G. (2014). Automated mapping of soybean and corn using phenology. Journal of Photogrammetry and Remote Sensing, 119, 151-164. https://doi.org/10.1016/j.isprsjp rs.2016.05.014

\section{Copyrights}

Copyright for this article is retained by the author(s), with first publication rights granted to the journal.

This is an open-access article distributed under the terms and conditions of the Creative Commons Attribution license (http://creativecommons.org/licenses/by/4.0/). 